\title{
A pesquisa etnográfica e sua importância para os estudos de aquisição de língua estrangeira
}

\author{
Denise de Souza Silva Pinto \\ Universidade Federal de Minas Gerais
}

\section{Abstract}

This article intends to give a general view of the discussions around a scientific method of classroom research called ethnography. This research method came from the social sciences with a clear concern for providing a cultural explanation of social groups. But, within the field of applied linguistics, the tradition of a quantitative view of research brought some other concerns to this research method, such as validity and reliability. However, in relation to the definition and to the essential elements of ethnography there is agreement among all authors. 


\section{INTRODUÇÃO}

pesquisa etnográfica tem despertado grande interesse em $A$ diversas áreas das ciências humanas que concebem o estudo 1 do comportamento humano necessariamente vinculado ao seu contexto social. Esta abordagem qualitativa é recente na área de pesquisas sobre aquisição de segunda língua (SLA) e língua estrangeira (FLA), se comparada ao volume de pesquisas experimentais e quantitativas. Este recente interesse justifica-se pela limitação dos resultados trazidos pela metodologia quantitativa tradicional na compreensão do processo de aprendizagem em sala de aula. Segundo Micolli (1997), as pesquisas quantitativas tradicionais focalizam suas análises no produto cognitivo/lingüístico dos aprendizes, sem analisar o contexto social da aprendizagem, ou seja, buscam a compreensão do processo indiretamente. Se a investigação dos processos sociais da sala de aula é realmente necessária para a compreensão do processo de aprendizagem, a etnografia tem um lugar importante na pesquisa em SLA. O escasso conhecimento sobre a sala de aula justifica uma abordagem capaz de descrever e interpretar este ambiente que ainda se apresenta como uma "caixa preta" para os estudos de SLA.

\section{DEFINIÇÃO}

Por etnografia entende-se a "descrição de um cultura ou de um grupo de pessoas que são portadoras de algum grau de unidade cultural" (Van Lier, 1988). A tarefa do etnógrafo é apresentada de diversas formas pelos autores:

"explicar o significado cultural revelado pelos comportamentos dos sujeitos estudados". (Nunan, 1992) 
"descrever e interpretar o comportamento cultural de um grupo". (Johnson, 1992)

As diversas concepções sobre a etnografia situam-se em um contínuo, cujas extremidades são denominadas por Van Lier (1988) como visão fraca e visão forte da etnografia. A visão fraca bastante comum na pesquisa de SLA, segundo o autor, considera a etnografia apenas como uma ferramenta, uma observação não sistemática do contexto, com a finalidade de gerar hipóteses e preparar terreno para a pesquisa experimental. A visão forte seria composta por aqueles que consideram a etnografia como metodologia geradora de teoria e fundamental para a abordagem humanística das ciências sociais.

\section{TIPOS DE ETNOGRAFIA}

Dois tipos de etnografia são considerados relevantes para a pesquisa de SLA segundo Johnson (1992): a educacional e a da comunicação. A primeira é definida por Spindler (1982, in Johnson, 1992, p. 133) como o "estudo de qualquer processo educacional, relacionado ou não com a escola”. Estão inseridos neste campo, portanto, os estudos de sala de aula com a seguinte questão central:

"como identificar, descrever e relacionar, em termos intersubjetivos, ações e contribuições dos participantes na sala de aula de L2, de tal forma que o seu significado para a aprendizagem da lingua seja entendido". (Van Lier, 1988)

O segundo tipo, etnografia da comunicação, centra sua investigação sobre aquilo que o falante precisa saber para comunicarse apropriadamente em uma comunidade lingüística e como este conhecimento é aprendido e usado. Segundo Johnson (1992), a importância destes estudos para a pesquisa de SLA está em fornecer uma forma de relacionar a aprendizagem da língua (também chamada de socialização de L2) com a aculturação. 


\section{PRINCÍPIOS HOLÍSTICO E ÊMICO}

Uma pesquisa pode ser conduzida de várias formas, mas só será etnográfica se estiver baseada em dois princípios básicos: holístico e êmico. Esta afirmativa parece ser consenso entre todos os autores que discutem a etnografia.

A busca da visão êmica dos acontecimentos consiste em considerar o contexto na perspectiva dos membros participantes daquele grupo. Esta busca constitui um desafio para os etnógrafos, pois, muitas vezes, o conhecimento sociocultural que motiva os participantes a se comportarem e se comunicarem da forma como fazem é implícito.

O princípio holístico consiste em sempre vincular os dados obtidos ao contexto, ou seja, garantir que todas as observações e interpretações sejam contextualizadas. Heath (1982, in Johnson, 1992, p. 147) traduz este princípio como a necessidade de relacionar os dados com o conhecimento já existente de outros componentes daquela cultura.

A abrangência deste contexto a ser considerado pela pesquisa e a relevância dos diversos tipos de contextos são discutidas por Johnson (1992). Partindo destes dois critérios, ela distingue o que chama de macroetnografia e microetnografia. A primeira seria o "estudo de eventos e processos de grande escala em relação com a comunicação e aprendizagem da L2, tais como a cultura de casa, valores culturais da comunidade e processos políticos" (Johnson, 1992). A microetnografia, por sua vez, trata dos "eventos e processos de pequena escala dentro da sala de aula e em outras interações comunicativas" (Johnson, 1992).

\section{NATUREZA ORGÂNICA DAS PERGUNTAS}

Os etnógrafos, em geral, iniciam suas pesquisas com perguntas abrangentes em relação ao seu objeto de estudo. Estas perguntas vão sendo especificadas a partir dos dados encontrados, levando-se sempre em consideração o contexto. Segundo Johnson (1992), a 
pesquisa etnográfica é como uma câmera fotográfica que sempre mantém o ambiente em vista, podendo, porém, movimentar o foco para captar detalhes de comportamentos, concentrando-se em questões mais refinadas.

\section{PROCEDIMENTOS DE COLETA}

\section{Trabalho de campo}

A coleta de dados da etnografia é essencialmente um trabalho de campo, ou seja, o estudo dos fenômenos é sempre conduzido no ambiente natural, onde os sujeitos normalmente vivem e trabalham. Ao mesmo tempo, é uma trabalho de relativa longa duração, segundo Nunan (1992). A justificativa para esta característica está na necessidade de o pesquisador familiarizar-se com o contexto e imergir nos dados, pois só desta forma ele será capaz de atender aos requisitos de uma análise social.

\section{Observação}

Os métodos utilizados na etnografia variam bastante e estão vinculados ao tipo de dados considerados relevantes pelo pesquisador. Porém, duas fontes de dados são apontadas pelos autores como principais: a observação (watching) e a pergunta (asking).

A observação é sem dúvida um aspecto central para a coleta de dados etnográfica. Johnson (1992) afirma que o etnógrafo confia mais em suas observações do que em qualquer outro instrumento. Há basicamente duas formas de se conduzir a observação, as assim chamadas "observação participada" e "não participada". Tradicionalmente, nas pesquisas de sala de aula, o papel assumido pelo pesquisador é de observador passivo. Johnson (1992) menciona que para autores como Hammerley e Atkinson, o etnógrafo deve tornase participante do contexto social. Estes afirmam inclusive que a etnografia define-se pela observação participante. O observador deve portanto ser de alguma forma co-participante no ambiente, a fim de que sua presença não cause estranheza e modifique as relações 
sociais naturais. Este dilema é chamado por Labov (1972, in Nunan, 1992, p. 65) de "paradoxo do observador", ou seja, o observador deseja ver o ambiente como ele se apresenta quando não é observado, porém só pode conseguir seus dados observando este ambiente. Alguns autores sugerem que o pesquisador assuma algumas funções periféricas no ambiente, sem porém sobrecarregarse de responsabilidades, para que seja possível sua tarefa de observador.

\subsection{Observação não avaliativa}

O relacionamento entre o etnógrafo e os participantes é necessariamente cooperativo, baseado na confiança e abertura. Este é um ponto crucial para pesquisa etnográfica, uma vez que ela depende dos sujeitos para lhe "entregarem" o conhecimento que têm de si. Neste ponto reside a incompatibilidade da função do pesquisador com o avaliador (encarado algumas vezes como espião). Segundo Van Lier (1988) as instituições que desejam encomendar uma pesquisa a fim de avaliar algum aspecto da educação dificilmente terão sucesso com a abordagem etnográfica.

\section{2. "Neutralidade" da observação}

Parece ser consenso atualmente dizer que nenhum trabalho de observação é totalmente objetivo, livre de julgamento de valor ou de alguma referência teórica. Na pesquisa em ciências humanas e principalmente em ambientes familiares ao pesquisador (como por exemplo a sala de aula), o desafio de não ser prescritivo é grande. Van Lier (1988) afirma que ser "neutro" para a etnografia significa garantir um trabalho de intersubjetividade, de convergência da perspectiva do observador e do participante. Para isto, é preciso que o observador explicite ao máximo o seu quadro de referência, as razões para seleção de seus elementos para observação e análise. A confiabilidade e a validade estão relacionadas com esta discussão e serão tratadas mais à frente. 


\section{Técnicas de elicitação}

O etnógrafo utiliza-se também de técnicas com algum grau de interferência (asking) quando necessita elicitar determinados dados de difícil inferência através apenas da observação. Dentre elas, incluem-se as entrevistas e os questionários. Johnson (1992) cita a definição de entrevista segundo Wolcott: "qualquer atividade que o pesquisador faça que introduza algo no ambiente natural a fim de obter intencionalmente alguma informação diretamente dos sujeitos". A autora aponta para a importância de se descobrir informantes chaves que estejam disponíveis e ao mesmo tempo sejam conhecedores do contexto estudado. As entrevistas podem ser de vários tipos, desde as estruturadas e formais, até as semi-estruturadas ou mesmo informais. Entretanto, é necessário que as técnicas sejam geradas in situ, como resultado da própria observação.

\section{Recursos escritos}

Outros recursos escritos são também utilizados pelos etnógrafos. Vários tipos de documentos são estudados, tais como programas de curso, planos de aula e documentos da escola, materiais do currículo, além de material produzido pelos alunos, como diários e amostras de sua escrita.

\section{Gravação dos dados}

Por fim, grande importância tem sido atribuída à técnica de gravação dos dados. A dificuldade de observar e registrar os eventos que ocorrem muitas vezes simultaneamente motiva a utilização da gravação não só como recurso mnemônico, mas também como instrumento de distanciamento (Van Lier, 1988), permitindo ao observador examinar o fenômeno com imparcialidade, perceber como a interação aparentemente caótica está estruturada e organizada, e buscar possíveis unidades de análise. 


\section{ANÁLISE DOS DADOS}

Quatro conceitos são apresentados por Johnson (1992) como importantes para se entender a análise etnográfica.

O primeiro deles é o caráter recursivo da análise, ou seja, a análise é feita paralelamente ao trabalho de campo. Baseado nela é que o etnógrafo toma suas decisões sobre novos procedimentos de coleta de dados e sobre a importância de focalizar alguns itens do contexto.

O segundo conceito decorre também do fato de a etnografia desenvolver-se com base nos dados. As categorias e conceitos são desenvolvidos de forma "que façam sentido e tenham relevância funcional para os participantes daquele ambiente" (Johnson, 1992). Tais categorias são refinadas e usadas para análise. É a descoberta desses padrões e da relação entre eles, segundo essa autora, que conduz à elaboração de um modelo teórico. Novas hipóteses podem ser geradas e verificadas com nova coleta de dados.

A clareza da análise é o terceiro conceito apontado por Johnson (1992). É necessário que a seleção de dados para análise seja sistemática e o critério dessa seleção seja explicitado para o leitor. Os exemplos devem ser também representativos dos dados observados.

Por último, a análise etnográfica pretende ir além da descrição dos fenômenos. Ela envolve a busca de explicações e interpretações da organização social por trás dos comportamentos descritos.

\section{VALIDADE E CONFIABILIDADE}

Estes critérios de avaliação das pesquisas foram desenvolvidos juntamente com a tradição experimental de pesquisas. A validade interna pretende medir se a relação de causa e efeito estabelecida entre as variáveis é verdadeira e a validade externa está relacionada com a possibilidade de generalização das descobertas da pesquisa para outros ambientes. Segundo Van Lier (1988), não faz parte dos objetivos da etnografia inferir sobre variáveis causais no ambiente, 
ou apresentar provas para suas previsões. Tampouco o padrão de generalização é adequado para o julgamento desta abordagem. Larsen-Freeman (1996) ao escrever sobre pesquisas qualitativas de sala de aula questiona se alguma vez já se atingiu a generalização nesta área e afirma que esta meta de generalização tem se tornado ainda mais remota atualmente. A etnografia deve portanto ser julgada de acordo com as determinações próprias deste desenho de pesquisa, ou seja, pelo seu "poder de criar uma compreensão de como as coisas acontecem do jeito que acontecem e porque fazem sentido para as pessoas" (Van Lier, 1988).

A confiabilidade também divide-se em dois tipos: externa e interna. A primeira relaciona-se com a replicabilidade do estudo e a segunda com a reanálise dos dados por um pesquisador independente. Nunan (1992) apresenta várias sugestões para garantir o atendimento a estes critérios na pesquisa etnográfica. Para garantir a possibilidade de replicação do estudo, o autor sugere que o pesquisador relate detalhadamente a metodologia utilizada, a escolha dos informantes, as condições sociais do contexto e a relação com o ambiente. Sugere também estratégias para garantir a confiabilidade externa: utilizar "descritores" de baixa inferência, submeter os dados ao exame de outros pesquisadores, gravar os eventos. Novamente, Van Lier (1988) defende que a pesquisa interpretativa deve ser avaliada em termos da "verdade" de seus resultados. É verdadeira a interpretação que esteja em consonância com o que foi descrito; e esta descrição por sua vez esteja sintonizada com o que foi observado no contexto. Esta sintonia determinará a adequação (das evidências) e o valor (contribuição para o conhecimento) dos resultados.

\section{CONCLUSÃO}

A etnografia caracteriza-se pela busca de dados diretamente das interações do contexto. A observação apresenta-se como componente mais importante para a abordagem etnográfica de pesquisa. O observador etnográfico dedica-se a estabelecer categorias e 
critérios para a classificação dos eventos da sala de aula. Os princípios holístico e êmico devem guiar esta descrição.

O debate entre os paradigmas interpretativos e experimentais está presente também na pesquisa em SLA. Não se deve, porém, tomar como verdadeiro o pressuposto de que um é cientificamente mais avançado que o outro. Ideal seria que cada um pudesse oferecer suas contribuições para o conhecimento nos limites estabelecidos por cada abordagem.

\section{BIBLIOGRAFIA CONSULTADA}

JOHNSON, Donna M. Approaches to research in second language learning. New York, London: Longman, 1992, p. 132-163.

LARSEN-FREEMAN, Dianne. The changing nature of Second Language Classroom Research, in Second Language Classroom Research: issues and oportunities. New Jersey: Lawrence Erlbaum Associates Publishers, 1996.

VAN LIER, Leo. The classroom and the language learner. London \& New York: Longman, 1988.

MICCOLI, Laura Stella. Learning English as a foreign language in Brazil: a joint investigation of.... University of Toronto, 1997. Tese de doutorado

NUNAN, David. Research methods in language learning. Cambridge: Cambridge University Press, 1992, p.52-73. 